\title{
Upgrading of Palm Oil Empty Fruit Bunches to Solid Fuel Using Torrefaction and Hydrothermal Treatment
}

\author{
D A Rahim ${ }^{1,2}$ M Yan ${ }^{2}$ R D A Pohan ${ }^{1}$ D Hantoko ${ }^{1,2}$ H Susanto $^{1 *}$ \\ ${ }^{1}$ Department of Chemical Engineering, Institut Teknologi Bandung, Bandung 40132, Indonesia \\ ${ }^{2}$ Institute of Energy and Power Engineering, Zhejiang University of Technology, Hangzhou 310014, People Republic \\ of China \\ ${ }^{*}$ Corresponding author.Email: herri@che.itb.ac.id
}

\begin{abstract}
To enhance the physicochemical properties of the EFB in the form of biochar, torrefaction and hydrothermal treatment were used. The proximate and ultimate compositions, heating values, and mineral composition of the biochar were all determined. The results showed that after treatment, fixed carbon increased while volatile matter decreased. With increasing reaction temperature, the increase and decrease were more noticeable. After hydrothermal treatment at 300 oC, the heating values of EFB increased from $19.05 \mathrm{MJ} / \mathrm{kg}$ to $29.31 \mathrm{MJ} / \mathrm{kg}$. As the reaction temperature rose, so did the energy densification. The contents of $\mathrm{Na}, \mathrm{K}$, and $\mathrm{Si}$ in EFB decreased after hydrothermal treatment, according to XRF results. In general, the ash content of biochar obtained through hydrothermal treatment was lower than that of EFB (4.54\%) as a raw material and comparable to Indonesian coal (37.37\%) as a comparison. As a result, hydrothermal treatment is preferable to torrefaction when it comes to converting biomass to high-quality solid fuel.
\end{abstract}

Keywords: Biomass, Biochar, Torrefaction, Hydrothermal Treatment, Heating Value

\section{INTRODUCTION}

Indonesia, as the world's largest producer of palm oil, also produces a lot of palm oil biomass [1]. Empty fruit bunches (EFB), palm shell, and husk are biomass produced during palm oil processing [2]. EFB, a form of palm oil biomass, may be used as a renewable energy source. EFB, on the other hand, has flaws such as a high alkaline content in the ash, a high moisture content, and a low heating value $[3,4]$. During biomass combustion, the high potassium and ash content can cause severe slagging and fouling [5]. Due to its low melting point, the formation of alkali silicates and alkali sulfates promotes bed agglomeration [6]. As a result, it is essential to work on improving the EFB fuel quality.

Torrefaction and hydrothermal treatment are two of thermal treatment method to convert biomass into highcalorific solids fuel [3]. During these processes, the water contained in the biomass as well as volatile mater are released, and cellulose, hemicellulose and lignin partly decompose giving off various types of volatiles [3]. The final product was the dry carbonized-biomass (biochar).
This study was aimed to compare the fuel quality improvement of the treated EFB via torrefaction (TR) and hydrothermal treatment (HT) against coal.

In a previous paper, a study on hydrothermal treatment for improving the fuel properties of empty fruit bunches at low temperatures was published [4]. In the present work, the hydrothermal treatment were compared to torrefaction at higher temperatures as pretreatment of EFB. The chemical properties of biochar, including proximate and ultimate properties, are discussed in this paper. Moreover, the fouling and slagging tendency are so discussed.

\section{MATERIAL AND METHODS}

\subsection{Material}

The EFB was obtained from a palm oil processing plant in Riau Province, Indonesia. The sample was shredded and dried in the sun in $2-3 \mathrm{~cm}$ lengths. Table 1 shows the results of EFB characteristic. 
Table 1. Properties of EFB

\begin{tabular}{|c|c|c|c|c|c|c|c|c|}
\hline \multicolumn{4}{|c|}{ Proximate analysis (wt\%, as received) } & \multicolumn{4}{c|}{ Ultimate analysis (wt\%, dry ash-free basis) } \\
\hline Moisture content & Volatile matter & Fixed carbon & Ash & C & H & O & N & S \\
\hline 8.63 & 70.85 & 16.36 & 4.15 & 52.51 & 7.33 & 38.89 & 1.02 & 0.25 \\
\hline
\end{tabular}

\subsection{Experimental set-up}

\subsubsection{Torrefaction.}

The experiments were carried out in a tubular reactor with an inner diameter of $3 \mathrm{~cm}$ and a length of $60 \mathrm{~cm}$. The reactor was electrically heated and its temperature was controlled. Five grams of EFB was loaded to the reactor, and volatiles produced during pyrolysis were carried out using nitrogen gas flow rate of $50 \mathrm{~mL} / \mathrm{min}$. The experiments were performed with temperatures ranging from $200-300{ }^{\circ} \mathrm{C}$. After completion of each experiment, the solid product was discharged from the reactor collected, and stored in sealed plastic bags before further analysis. The detailed configuration of experiment setup for torrefaction was described in previous paper [4].

\subsubsection{Hydrothermal treatment.}

The experiments of HT were conducted in a digester with temperatures ranging from $200-300{ }^{\circ} \mathrm{C}$. The digester pressure was not observed using a pressure gauge and it was ranging from 1.6 to $9.4 \mathrm{MPa}$. In each experiment, 20 grams of EFB were used, with a 1:5 (w/w) ratio of EFB to water. To purge air, nitrogen gas was first passed through the digester for 10 minutes. The reactor was preheated to the desired temperature and then kept there for 60 minutes. Vacuum filtration $0.45 \mathrm{~m}$ Polyvinylidene fluoride (PVDF) membrane was used to collect the solid product and separate it from the liquid, which was then dried at $105^{\circ} \mathrm{C}$ in the oven before further analysis. The detailed configuration of the digester was described in [4].

\subsection{Analytical methods}

Several characterization methods were used to investigate the properties of the biochar. The proximate analysis was calculated using the CHNS analyzer in accordance with ASTM D.5373 and ASTM D.4239, and the ultimate analysis was determined using the ASTM D.5373 and ASTM D.4239. Heating value of biochar was analyzed using Bomb Calorimeter based on ASTMD.5865. An X-ray fluorescence spectrophotometer (XRF, ARL ADVANT'X Thermo Electron Corp) and a scanning electron microscope with an energy dispersive X-ray detector (SEM-EDS, FESEM, Hitachi S-4700, Japan) were used to examine the mineral composition of ash. Empirical equations based on the mineral composition of biochar ash were used to determine slagging and fouling characteristics such as base/acid ratio, slag viscosity index, $\mathrm{Si}-\mathrm{Al}$ ratio, fouling index, slagging index, and alkali index [8].

\section{RESULTS AND DISCUSSION}

\subsection{Energy densification of biochar}

The effect of TR and HT of EFB on the mass yield, energy densification, and energy yield are illustrated in Figure 1. The temperature of HT and TR greatly influenced the yield of biochar. Both treatments provided similar trends in the decrease in yields of biochar when the temperature increased. The decrease in yields of biochar was affected by thermal degradation of biomass. The result showed that mass yield of HT was lower than TR due to the degradation of biomass during HT occurred at higher pressure compared to TR.

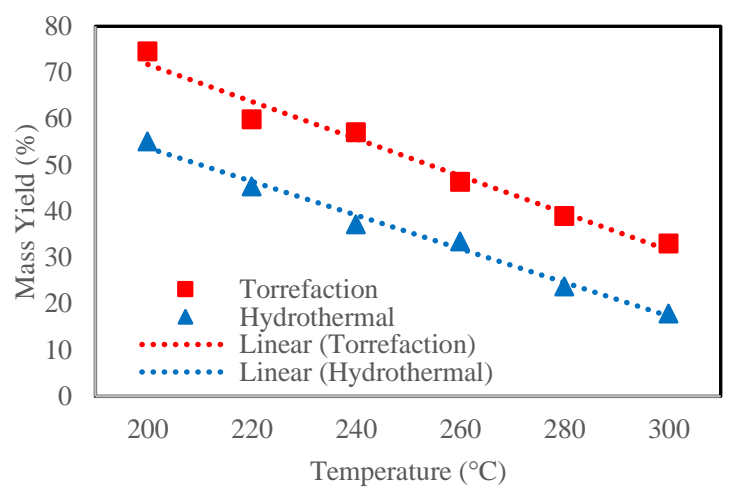

(a) Mass yield of biochar

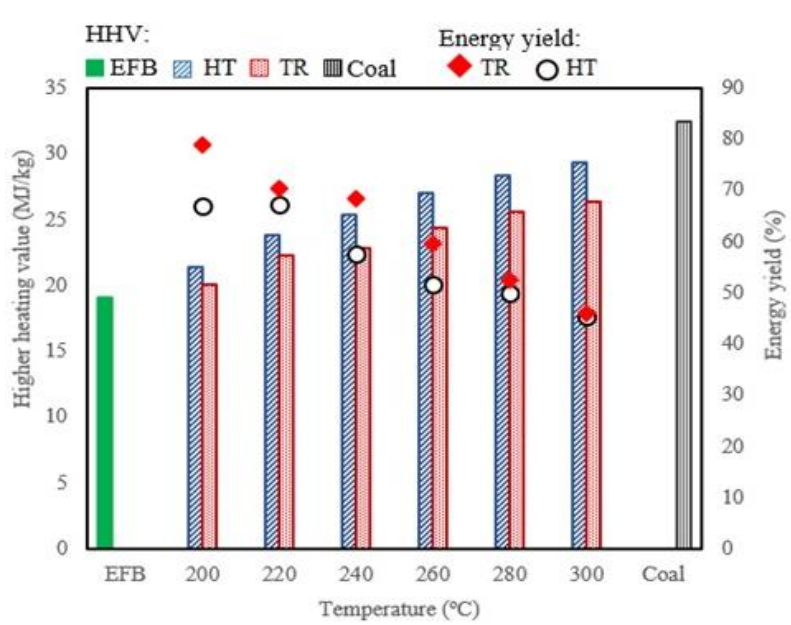

(b) (b) Heating value and energy yield of biochar

Figure 1 Effect of TR and HT on yields 
As shown in Figure 1 for both TR and HT, the higher heating value of biochar increased with the increase of temperature, while the energy yield decreased. The results showed that HT was more effective than TR for upgrading the heating value of EFB. The energy yield (multiplication of mass yield and heating value) of biochar via TR tended higher than that of HT, although it became equal to the other at $300{ }^{\circ} \mathrm{C} ; 45.87 \%$ for TR and $45.48 \%$ for HT.

\subsection{The chemical properties of biochar}

Large increases in volatile matter and fixed carbon may also indicate thermal degradation of biomass. TR and HT had shown to be able for upgrading proximate and ultimate analysis of biomass into biochar. Both treatments helped to decrease the volatile matter (VM) and to increase the fixed carbon (FC) of the biochar with an increase in the reaction temperature, as shown in Figure 2. Generally, biomass has a very high VM, it makes low combustion efficiency and high harmful emissions when directlycombusted [5]. While FC improves the calorific value of solid fuel. Based on VM and FC, both biocharswere similar to coal. Even their FC and VM of biochars produced at a temperature above 280 ${ }^{\circ} \mathrm{C}$, was better thana typical rank of coal from Indonesian coal (lignite)

The heating value may be associated with the elemental composition of solid fuels [8]. In TR and HT, the energy content of biochar increased, which was linked to a decrease in the number of low energy $\mathrm{H} / \mathrm{C}$ and $\mathrm{O} / \mathrm{C}$ bonds (decreasing $\mathrm{H} / \mathrm{C}$ and $\mathrm{O} / \mathrm{C}$ ratios) and an increase in the number of high energy $\mathrm{C}-\mathrm{C}$ bonds [9]. In the range of $200-300{ }^{\circ} \mathrm{C}$, the carbon content of biochar increased and oxygen content decreased with increasing temperature (Figure 3). TR contributed more significant improvements to the elemental composition of biochar than HT. But at $300{ }^{\circ} \mathrm{C}$, the carbon and oxygen composition of TR-biochar and HT-biochar were more or less the same, i.e.: $69.55 \%$ and $16.82 \%$ for TR, $70.93 \%$ and $15.79 \%$ for HT, respectively. Dehydration, condensation, hydrolysis, demethanation, and decarboxylation are all processes involved in lignocellulosic HT [9]. As a result, HT contains a variety of compounds dissolved in the liquid residue, in addition to solid and gaseous materials.

\subsection{Ash content and compositions}

Ash content is opposite in fixed carbon content, it can reduce the energy density of fuel. Biomass generally has lower ash content than coal, except for sewage sludge and municipal solid waste [4]. However, many biomass, especially agricultural wastes (e.g., empty fruit bunches, sugarcane bagasse, etc.), contain high levels of alkali metal in their ash, causing slagging and fouling issues.

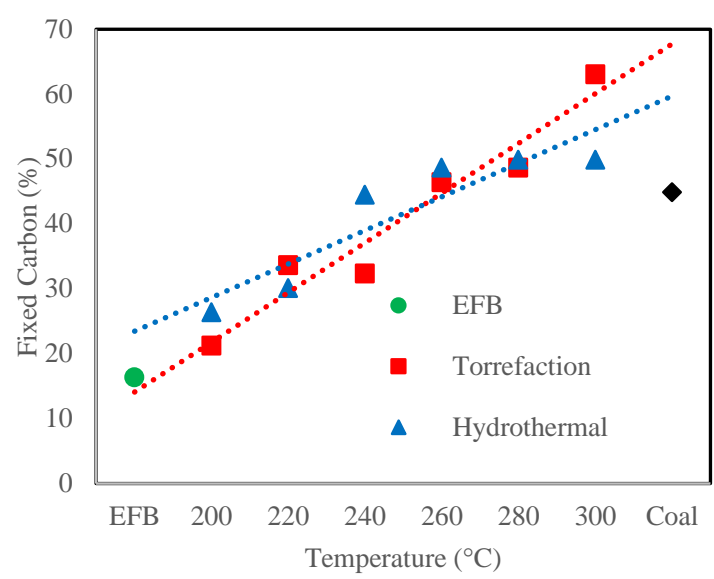

(a) Fixed carbon content

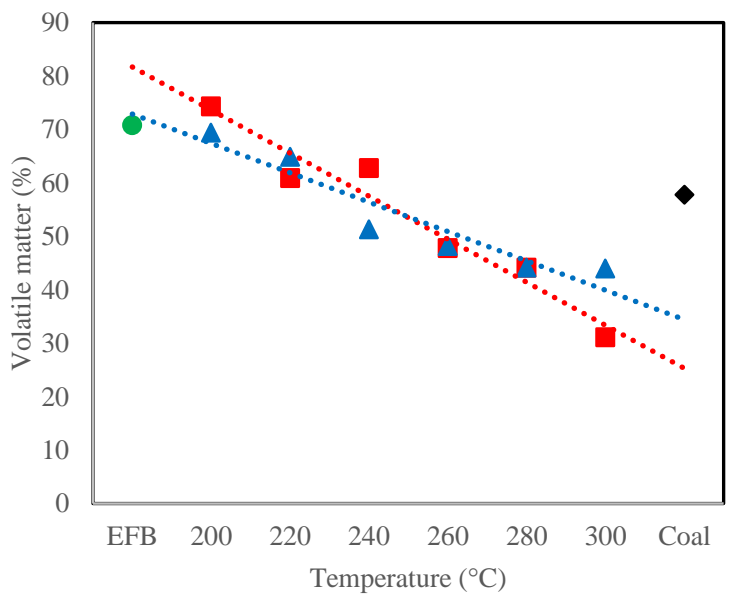

(b) volatile matter content

Figure 2 Effect TR and HT on biochar and volatile matter contents char (wt\%, dry basis)

As shown in Figure 4, the ash content in TR-biochar increased with increasing temperature, so the quality of biochar become worse than EFB. In contrast, in HT, the use of hot, high-pressure water as a reaction medium can dissolve some minerals in the ash., resulting in lower of ash content in HT-biochar compared to TR-biochar. Moreover, the ash content of HT-biochar (process temperature up to $280^{\circ} \mathrm{C}$ ) was significantly lower than EFB (about $3.5 \%$ vs $4.54 \%$ ), and it was more or less the same with a typical Indonesian coal (3.74\%). As a result, hydrothermal treatment was deemed to be more suitable for upgrading EFB to a solid fuel than torrefaction. 


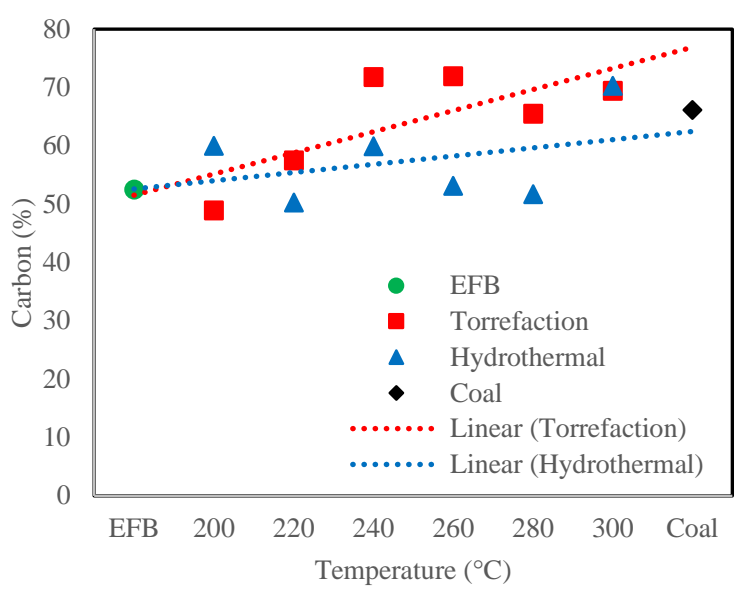

(a) carbon content

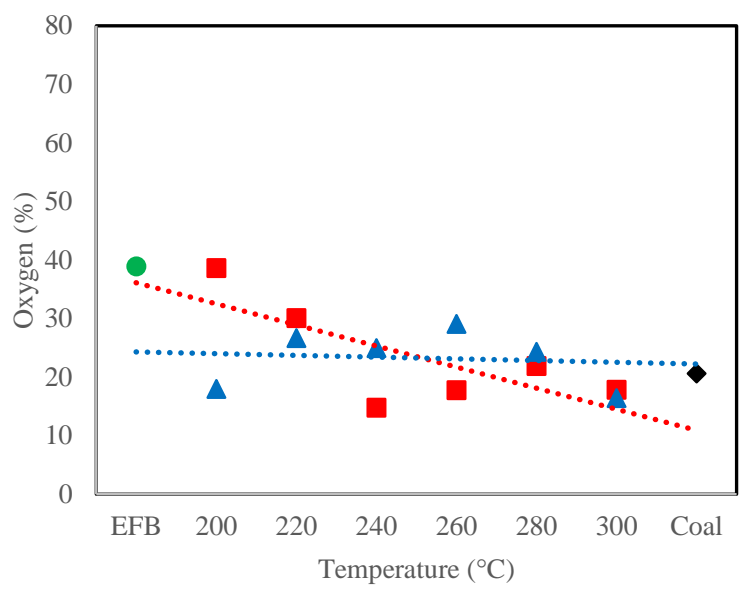

(b) oxygen content

Figure 3 Effect of TR and HT treatment on carbon and oxygen content in biochar (wt\%, dry basis)

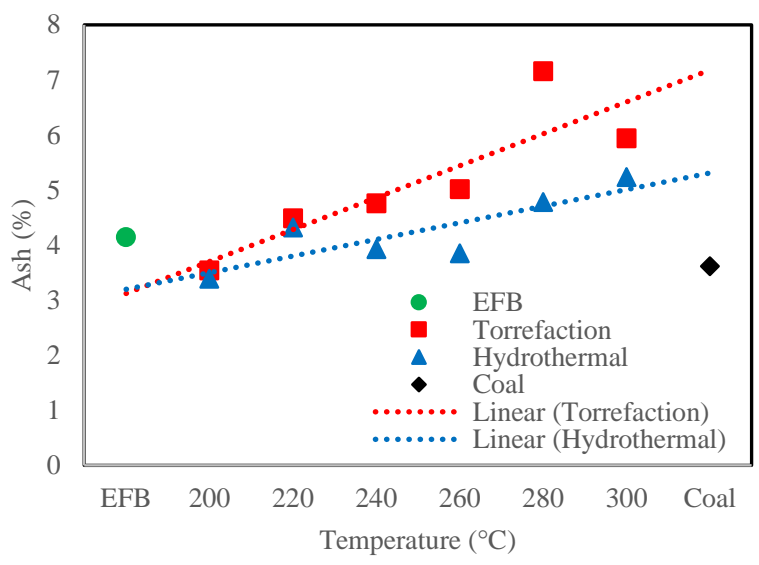

Figure 4 Ash content of TR-biochar and HT-char (wt\%, dry basis)
The effects of HT on the mineral composition of ash were further analyzed using SEM-EDS and XRF (see Table 2). The major improvement in ash content in the solid product of HT, as well as the decrease in potassium content in the residual ash, were the most promising findings in this study. Since potassium and sodium are instantly dissolved in water, their concentration in HTbiochar ash decreased significantly. The concentrations of $\mathrm{SiO}_{2}$ and $\mathrm{Al}_{2} \mathrm{O}_{3}$ in HT-biochar ash, on the other hand, increased, owing to significant reductions in potassium and sodium content. $\mathrm{Fe}_{2} \mathrm{O}_{3}$ and $\mathrm{CaO}$ concentrations in HT-biochar ash showed similar trends, albeit in the opposite direction.

\subsection{Fouling, slagging, and alkali indices}

Slagging and fouling are the most common problems in biomass use, and they can put a biomass power plant's operation in trouble. The mineral composition of ash can be used to determine slagging and fouling characteristics such as base/acid ratio, slag viscosity index, $\mathrm{Si}-\mathrm{Al}$ ratio, fouling, slagging, and alkali index. [8]. The fouling and slagging tendencies of HT are shown in Table 2.

Results on the experimental measurements on ash fouling temperature was reported in [10]. For simulating a co-firing, HT-biochar and the typical Indonesian coal were mixed in portions of 1:2, 1:1, and 2:1. Under the oxydizing atmosphere, the measured ash deformation temperature increased significantly with increasing the portion of HT-biochar: 1185, 1208 and $1205{ }^{\circ} \mathrm{C}$ respectively. While the ash flowing temperature changed slightly: 1123,1233 and $1228{ }^{\circ} \mathrm{C}$. Based on these ash fusion properties, it was convinced that the use of hydrothermal treatment was more advantageous than torrefaction. But further investigations should be conducted for the effect of hydrothermal treatment on the biochar ash fusion temperature, because there has been a growing interest on the use of empty fruit bunches and palm kernel shell as solid fuels in chemical plants, such as in power boiler, cement and ceramic factories.

\section{CONCLUSIONS}

Torrefaction and hydrothermal treatment have been shown to increase the energy densification, proximate and ultimate analysis, and ash composition of EFB as a solid fuel. The physicochemical properties of biochars were much different to $\mathrm{EFB}$, and close to a typical Indonesian coal. Because of the lower ash content in the HT process, fouling and slagging are less likely to occur when biochar is used as a solid fuel. Based the biochar characteristics, hydrothermal treatment had been considered to be better than torrefaction for biomass upgrading to solid fuel. 
Table 2. Ash composition, slagging and fouling characteristics

\begin{tabular}{|c|c|c|c|c|c|c|c|c|c|}
\hline & EFB & HT-150 [4] & HT-200 & HT-220 & HT-240 & HT-260 & HT-280 & HT-300 & Coal \\
\hline \multicolumn{10}{|c|}{ Ash composition of EFB, biochars, and coal (\%wt) } \\
\hline $\mathrm{SiO}_{2}$ & 37.29 & 56.63 & 39.54 & 28.61 & 56.18 & 43.26 & 29.65 & 26.03 & 32.09 \\
\hline $\mathrm{Al}_{2} \mathrm{O}_{3}$ & 4.12 & 1.95 & 8.98 & 2.01 & 0.90 & 2.34 & 1.26 & 0 & 11.76 \\
\hline $\mathrm{Fe}_{2} \mathrm{O}_{3}$ & 4.41 & 1.70 & 2.51 & 1.03 & 1.56 & 1.83 & 1.60 & 2.14 & 28.28 \\
\hline $\mathrm{K}_{2} \mathrm{O}$ & 19.06 & 15.87 & 24.03 & 40.59 & 22.19 & 23.51 & 31.59 & 59.17 & 0.33 \\
\hline $\mathrm{Na}_{2} \mathrm{O}$ & 0.20 & 1.15 & 0.85 & 1.16 & 0.50 & 0.34 & 0.15 & 0 & 2.03 \\
\hline $\mathrm{CaO}$ & 25.78 & 14.63 & 16.49 & 20.42 & 12.59 & 21.33 & 25.53 & 0 & 15.72 \\
\hline $\mathrm{MgO}$ & 9.15 & 7.80 & 7.60 & 6.18 & 6.08 & 7.38 & 10.22 & 12.65 & 8.83 \\
\hline \multicolumn{10}{|c|}{ Slagging and fouling characteristics } \\
\hline Base/acid ratio & 1.42 & 0.70 & 1.06 & 2.27 & 0.75 & 1.19 & 2.24 & 2.84 & 1.26 \\
\hline Slag viscosity index & 48.66 & 70.12 & 59.78 & 50.88 & 73.52 & 58.62 & 44.25 & 63.77 & 37.79 \\
\hline Fouling index & 27.26 & 11.96 & 26.40 & 94.59 & 17.06 & 28.45 & 70.96 & 168.13 & 2.97 \\
\hline Slagging index & 0.35 & 0.08 & 6.72 & 13.46 & 1.68 & 4.53 & 21.98 & 1.30 & 0.33 \\
\hline Alkali index & 19.26 & 17.02 & 24.88 & 41.75 & 22.69 & 23.85 & 31.74 & 59.17 & 2.36 \\
\hline
\end{tabular}

\section{ACKNOWLEDGMENTS}

This work was financially supported by P3MI 2018 Research Grant, Institut Teknologi Bandung, Indonesia; the National International Cooperation Project (2016YFE0202000, 2017YFE0107600), China; and Zhejiang Natural Science Foundation Project (LY17E060005), China.

\section{REFERENCES}

[1] Paltseva J, Searlw S, Malins C. Potential for Advanced Biofuel Production from Palm Residues in Indonesia. White Paper: The International Council on Clean Transportation (ICCT). 2016.

[2] Jamari SS, Howse JR. The effect of the hydrothermal carbonization process on palm oil empty fruit bunch. BiomassBioenergy.2012;47:82-90.

[3] Novianti S, Nurdiawati A, Zaini IN, Prawisudha P, Sumida H, Yoshikawa K. Low-potassium fuel production from empty fruit bunches by hydrothermal treatment processing and water leaching. Energy Procedia. 2015;75:584-589.

[4] Hantoko D, Yan M, Prabowo B, Susanto H. Preparation of empty fruit bunch as a feedstock for gasification process by employing hydrothermal treatment. Energy Procedia. 2018;152:1003-8.
[5] Khan AA, de Jong W, Jansens PJ, Spliethoff H. Biomass combustion in fluidized bed boilers: Potential problems and remedies. Fuel Processing Technology. 2009;90:21-50.

[6] Wang Y, Wang D, Dong C, Yang Y. The behaviour and reactions of sodium containing minerals in ash melting process. Journal of the Energy Institute.2017;90:167-73.

[7] Yan M, Hantoko D, Susanto H, Ardy A, Waluyo J, Weng Z, Lin Jie. Hydrothermal treatment of empty fruit bunch and its pyrolysis characteristics. Biomass Conversion and Biorefinery. 2019;9:709-717.

[8] Zhu Y, Niu Y, Tan H, Wang X. Short review on the origin and countermeasure of biomass slagging in grate furnace. Frontriersin Energy Research. 2014;2:7.

[9] Hu X, Li X, Luo G, Yao H. Homogeneous and heterogeneous contributions of $\mathrm{CO}_{2}$ and recycled NO to NO emission difference between air and oxy-coal combustion. Fuel. 2016;163:1-7.

[10] Yan M, Rahim DA, Susanto H, Pohan RDA, Hantoko D.Impact of biomass upgrading via hydrothermal treatment on slagging and fouling during cofiring with coal. Paper presented at the $26^{\text {th }}$ Regional Symposium on Chemical Engineering 2019, Kuala Lumpur, Malaysia, October 2019. 